\title{
Flawed analytical method used for reference glucose
}

\author{
George Cembrowski, MD, PhD
}

Received: 9 May 2019/Revised: 17 May 2019/Accepted: 17 May 2019/Published online: 9 July 2019

(c) Canadian Anesthesiologists' Society 2019

\section{To the Editor,}

The work of Nakadate et al. ${ }^{1}$ shows poor non-early morning glucose agreement when arterial whole blood glucose is measured by the NOVA StatStrip ${ }^{2}$ and the Instrumentation Laboratory GEM Premier 3000 blood gas analyzer. In their study, the GEM 3000 instrument provided the reference glucose values for the comparative StatStrip glucoses. The authors compared the glucose levels of over 100 patients during five measurement periods related to cardiac surgery: 1) baseline, 2) before cardiopulmonary bypass (CPB) but after heparinization, 3) $30 \mathrm{~min}$ after full $\mathrm{CPB}, 4)$ two hours after full $\mathrm{CPB}$, and 5) $30 \mathrm{~min}$ after separation of $\mathrm{CPB}$ and the administration of protamine. The authors attribute this unacceptable correlation to the interference in the StatStrip ${ }^{\circledR}$ Glucose Hospital Meter System (Nova Biomedical, Waltham, MA, USA) measurement by heparinized, lower hematocrit blood.

I offer a simpler potential explanation. The GEM ${ }^{\circledR}$ Premier $^{\mathrm{TM}} 4000 \AA$ (Instrumentation Laboratory Company, Bedford MA, USA) blood gas analyzer, a newer version of the GEM $3000 \AA$, shows optimally low imprecision in the early morning, coincident with the daily ( 2 a.m.) analysis of calibrator solution. ${ }^{3}$ The imprecision then increases, reaching peak inaccuracy at six to eight hours post calibration. $^{2,4}$ Glucose, sodium, potassium, and hemoglobin are the most affected. Glucose analyses by the GEM 3000 and the GEM 4000 are equivalent with both

This letter is accompanied by a reply. Please see Can J Anesth 2020; 67: this issue.

\section{G. Cembrowski, MD, PhD ( $\square)$}

Department of Laboratory Medicine and Pathology, University of Alberta, Edmonton, AB, Canada

e-mail: cembr001@gmail.com systems being used interchangeably at Vanderbilt University Medical Centre. ${ }^{5}$ Nakadate's concordant baseline measurements occur in the early morning and the next four, non-concordant measurements encompass the later morning and early afternoon periods. The imprecision of the GEM glucose measurement roughly doubles between early morning and subsequent periods and invalidates the authors' conclusions about the StatStrip's impaired performance. The GEM hemoglobin imprecision also increases by around two thirds. It is virtually impossible to transform Nakadate's diagrams that document accuracy into measures of imprecision.

I believe that most GEM users are unaware of the intraday increases in variation. We have previously outlined approaches to measure and document the GEM's timedependent expansion of variation including running quality control material in the evening or comparing the results of testing patient specimens on tandem systems in the morning and evening.

Conflicts of interest None declared.

Editorial responsibility This submission was handled by Dr. Hilary P. Grocott, Editor-in-Chief, Canadian Journal of Anesthesia.

Funding None.

An honorarium was received from LifeScan for the rewriting of a Diabetes Educator review of how to assess whole blood glucose meter performance. No other funds have been received in the last two years from any diagnostic company.

\section{References}

1. Nakadate $Y$, Sato H, Roque $P$, et al. Accuracy of blood glucose measurements using the NOVA StatStrip ${ }^{\circledR}$ glucometer during 
cardiac surgery: a prospective observational study. Can J Anesth 2019. DOI: https://doi.org/10.1007/s12630-019-01350-7.

2. Musholt PB, Schipper $C$, Thomé $N$, et al. Dynamic electrochemistry corrects for hematocrit interference on blood glucose determinations with patient self-measurement devices. J Diabetes Sci Technol 2011; 5: 1167-75.

3. Cembrowski GS, Xu Q, Cembrowski AR, Mei J, Sadrzadeh H. Impaired clinical utility of sequential patient GEM blood gas measurements associated with calibration schedule. Clin Biochem 2017; 50: 936-41.
4. Kattar M, Xu Q, Cembrowski A, Mei J, Sadrzadeh H, Cembrowski $G S$. Reduced accuracy of GEM 4000 for measurement of electrolytes, glucose, and hemoglobin in relation to calibration schedule. Am J Clin Pathol 2018; 149(Suppl 1): S8.

5. Liang Y, Wanderer J, Nichols JH, Klonoff D, Rice MJ. Blood gas analyzer accuracy of glucose measurements. Mayo Clin Proc 2017; 92: 1030-41.

Publisher's Note Springer Nature remains neutral with regard to jurisdictional claims in published maps and institutional affiliations. 